\title{
A Importância dos Programas de Extensão no Ensino e Prática de Programação e Desenvolvimento de Protótipos
}

\author{
Elany Marinho B. Farias ${ }^{1}$, Pio Ferreira L. Netto ${ }^{1}$, Caroline Peixoto Pilletti ${ }^{1,2}$, \\ Enoque Calvino Melo Alves ${ }^{1}$ \\ ${ }^{1}$ Instituto de Engenharia e Geociências - Universidade Federal do Oeste do Pará \\ (UFOPA) \\ Caixa Postal 68.040-470 - Santarém - PA - Brasil \\ ${ }^{2}$ Centro de Ciências Exatas e Tecnologia - Faculdades Integradas do Tapajós (FIT) \\ \{elany7, pio.lima, carolineppilletti, enoque\}@gmail.com
}

\begin{abstract}
This paper describes the importance of applied research with newly freshmen in college studying Introduction to Computer Science (ICS), demonstrated through a case study of two projects undertaken by the applied research Midias Eletrônicas: Ensino e Inclusão. The goals of this research is to present information related to student performance, highlighting their participation in projects for better assessment of subjects learned in the classroom, contributing for a reflection on adapting the university to improve the teaching-learning methodologies.
\end{abstract}

Resumo. Este artigo descreve a importância dos projetos extensionistas com alunos recém-ingressantes na universidade que estudam Introdução à Ciência da Computação (ICC), demonstrada através de um estudo de caso com dois projetos realizados pelo Programa de Extensão Mídias Eletrônicas: Ensino e Inclusão. O objetivo desta pesquisa é apresentar informações relacionadas ao desempenho dos alunos, destacando a participação destes nos projetos para uma melhor fixação dos assuntos aprendidos nas salas de aulas, contribuindo para uma reflexão na adaptação da universidade para a melhoria nas metodologias de ensino-aprendizagem.

\section{Introdução}

Entende-se por extensão universitária como uma ação conjunta da universidade com a comunidade, desse modo contribuindo para a construção de novos e diferentes saberes, possibilitando a troca de experiências e a participação efetiva na atuação da universidade no seu meio social. Visto que a universidade baseia-se no ensino e pesquisa, a integração da extensão forma um tripé acadêmico fundamental para promover o encontro do conhecimento universitário com a realidade local.

Considerando que a sociedade se transforma seguindo ritmos diferentes devido ao constante surgimento de tecnologias, é uma das responsabilidades da universidade se adequar a esta em busca de compreender o despertar de novas possiblidades e as formas que podem ser aplicadas nas metodologias de aprendizagem. 
Partindo desse principio, na área da computação, tem-se observado que durante o processo de aprendizagem na disciplina obrigatória de Introdução à Ciência da Computação (ICC), onde são abordados assuntos como algoritmos e introdução à lógica da computação, é detectado que, por parte dos alunos iniciantes, há dificuldades em assimilar as abstrações e o raciocínio lógico causando assim grande índice de reprovações. A proposta deste artigo é apresentar uma análise das atividades extensionistas para a produção e disseminação do conhecimento, enfatizando ações na área da computação e sua influência na vida acadêmica, com a ênfase na experiência dos alunos bolsistas do Programa de Extensão Mídias Eletrônicas: Ensino e Inclusão.

\section{Referencial Teórico}

De acordo com o Art.207 da Constituição Federal de 1988, "As universidades gozam de autonomia didático-científica, administrativa e de gestão financeira e patrimonial, e obedecerão ao princípio de indissociabilidade entre ensino, pesquisa e extensão" (BRASIL, 1988), ou seja, o artigo em questão estabelece uma pauta para reflexão para que as universidades com sua autonomia desenvolvam atividades integrando esses três eixos de forma complementar, promovendo a transformação, disseminação e criação do conhecimento através da união da teoria e prática.

Partindo desse principio, a integração do ensino, pesquisa e extensão forma um tripé que tem como finalidade aproximar o saber acadêmico com a realidade, em que a pesquisa é a geradora de novos conhecimentos e a sua propagação acontece por meio do ensino e extensão atuando de forma metódica. Os programas de extensão desenvolvem projetos educacionais que agregam valores a todos os envolvidos, em um conjunto articulado de projetos e outras ações de extensão, preferencialmente de caráter multidisciplinar e integrado a atividades de pesquisa e de ensino com o prazo estendido.

Para Borges (2013) o conceito de extensão "se alia a essas duas grandes bases do Ensino Superior ao permitir a prática do conhecimento aprendido na academia, buscando uma maior integração com a realidade e as demandas da Sociedade". Assim é possível entender que os programas de extensão revelam-se em grande importância pela possibilidade de desenvolvimento de processos de ensino-aprendizagem a partir de práticas diárias, do envolvimento das partes interessadas e todo o conhecimento que ele gera.

\subsection{Atividades extensionistas de ensino de programação}

No que diz respeito à área da Computação, a maioria dos relatos de atividades de extensão tem como público alvo alunos de ensino médio como cita Garcia (et al. 2008) em seu trabalho de relato da experiência obtidas no ensino de lógica de programação e estrutura de dados com o objetivo principal de estimular e despertar o interesse desses alunos para a área da Computação. Com relação à Lógica de Programação, Pereira Júnior e Rapkiewicz (2004, apud Garcia et al, 2008) apontam que, durante o processo de ensino-aprendizagem de fundamentos de programação, grande parte dos alunos apresenta dificuldades em assimilar as abstrações envolvidas, havendo dificuldade em formalizar soluções a partir das abstrações.

As disciplinas relacionadas aos conceitos fundamentais da Computação são as que mais colaboram para os altos índices de reprovação e provocam a maioria da evasão 
de alunos. Macedo \& Prietch (2011) afirmam que é possível tornar esses conteúdos mais atrativos e palpáveis, utilizando ferramentas diferentes para o ensinoaprendizagem. Essa busca pode ser realizada pelos alunos extensionistas e alunos recém-ingressantes, estimulando no convívio dos projetos o contato imediato destes com ferramentas em que facultam uma melhor fixação e aplicação de conceitos aprendidos na sala de aula, possibilitando também a troca de conhecimentos e uma visão de um panorama amplo das possiblidades durante e depois da graduação.

\subsection{Mídias Eletrônicas: Ensino e Inclusão}

Contabilizando quase três anos de ação, o Programa de Extensão Mídias Eletrônicas: Ensino e Inclusão, atua na Universidade Federal do Oeste do Pará, na cidade de Santarém. O primeiro ano integrou ações em oito escolas públicas de zonas periféricas com atividades conhecidas como "Clube do conhecimento", ensinando alunos de ensino médio a utilizar ferramentas digitais tais como: edição de áudio e vídeo e atividades para o ensino básico de programação com Scratch e o kit Lego Mindstorms.

No segundo ano as linhas de ações foram nas escolas públicas e a outra no desenvolvimento de atividades voltadas aos alunos recém-ingressantes na Universidade. O desenvolvimento de atividades aos acadêmicos teve como proposta ser um trabalho para a obtenção de nota extra na disciplina de ICC, estimulando dessa forma o entendimento da matéria de forma prática. No decorrer deste ano, as atividades do programa deram ênfase ao ensino-aprendizagem de programação para acadêmicos mas com uma oferta maior de ferramentas para que estes desenvolvessem um projeto no final do semestre. As ferramentas trabalhadas foram: Arduino, criação de jogos com Game Maker e Blender e robótica com o Kit Lego Mindstorms.

\section{Metodologias e Ferramentas Utilizadas}

Os projetos desenvolvidos pelo Mídias Eletrônicas: Ensino e Inclusão são gerenciados segundo os conceitos de gerenciamento de projetos do PMBOK (PMI, 2013) e a metodologia Scrum com alinhamento segundo a abordagem de Cruz (2013), fundamentados no pensamento de Moura \& Barbosa (2011) que visualizam os projetos educacionais sendo gerenciados com as técnicas e ferramentas de gerenciamento de projetos.

Para os projetos realizados foram selecionados oito alunos divididos em duas equipes. Os encontros aconteciam três vezes na semana totalizando seis horas semanais durante o período de um mês e meio. Ficou estabelecido um bolsista como tutor para cada equipe. O processo para a aplicação do projeto ficou dividido em quatro etapas importantes.

A primeira etapa foi a divulgação nas salas de aulas com o intuito de convidar os alunos a se voluntariar para participar do projeto, no intermeio disso houve o workshop para apresentação das ferramentas e depois a inscrição e seleção dos alunos. A segunda etapa foi o planejamento que teve inicio com a definição do protótipo que iam desenvolver. Foi aplicado o método de gerencia de projeto com o Project Model Canvas. A proposta ao utilizar o canvas foi aperfeiçoar o processo de desenvolvimento do protótipo para uma melhor visualização e elaboração dos objetivos, justificativas e definição de tarefas. 
A ferramenta que serviu de base para os projetos foi a placa de prototipagem eletrônica Arduino, que permite construir sistemas embarcados que percebam a realidade e respondam com ações, utilizando uma linguagem de programação própria baseada em C. Foi projetada com a finalidade de ser de fácil entendimento, programação e desenvolvimento. A etapa de execução começou primeiramente com as atividades de apresentação de aulas expositivas para a fundamentação teórica necessária para o conhecimento da ferramenta e depois se deu inicio a sequência de testes dos componentes e o desenvolvimento do código. A quarta e última etapa deu-se o encerramento no seminário de apresentação dos resultados.

\subsection{Projeto Segurança na Boate}

Foi proposto aos alunos que ao pensar no projeto final, levassem em consideração problemas reais, nessa perspectiva o projeto desenvolvido teve como embasamento o incêndio que ocorreu na Boate Kiss em Santa Maria/RS em 27 de Janeiro de 2013 que matou 242 pessoas. De acordo com as investigações, a banda que estava se apresentando no momento, utilizou um sinalizador de uso externo que soltou faíscas que atingiram o teto causando o incêndio. A partir de então, outros fatores colaboraram para a tragédia, como: a superlotação do ambiente, a falta de comunicação e a falta de sinalização para a saída de emergência.

Com base nos principais problemas apontados, os alunos desenvolveram um protótipo de uma boate em que constava um contador de entrada e saída de pessoas utilizando leds infravermelhos, quando atingia o limite de pessoas no ambiente soava um alarme. Ao mesmo tempo a temperatura era monitorada utilizando-se um sensor que identificava quando o ambiente estava numa temperatura alta. Estruturalmente o protótipo foi desenvolvido com melhorias, como a sinalização das saídas de emergência e o acréscimo de uma sala de controle.

\subsection{Projeto Estacionamento Inteligente}

Para o segundo projeto também com baseado em problemas reais, a ideia de um controle de vagas de estacionamento, tendo como embasamento o problema para encontrar uma vaga em estacionamentos de grandes shoppings centers, onde o cliente do shopping entra sem saber se há vagas no estacionamento, e perde algum tempo procurando a vaga.

Com base nessa problemática, os alunos desenvolveram um protótipo de um estacionamento, contendo as vagas dos carros e cada vaga possuía um sensor de distancia. Ele controlava a presença ou não de um veiculo. E ao mesmo tempo, este sensor também acionava na entrada do estacionamento, um display mostrava a quantidade de vagas ocupadas e a quantidade de vagas livres no estacionamento.

\subsection{Resultados Obtidos}

As observações dos monitores das equipes permitiu concluir que os alunos absorveram de forma rápida e criativa o assunto ensinado, buscando por soluções cabíveis à medida que apareciam alguns problemas tanto na estrutura que estavam desenvolvendo quanto no código que tentavam implementar. Porém ficou explicito as dificuldades dos alunos logo no inicio ao tentarem entender o funcionamento dos componentes que iam utilizar para aplicação no projeto e pelo curto prazo para a entrega do protótipo. 
Em relação aos alunos extensionistas que foram monitores das equipes, as dificuldades foram também em relação à falta de tempo para organizar os encontros. Porém, ao final do tempo determinado os protótipos alcançaram os objetivos iniciais deixando assim pontos que foram positivos em relação a metodologia utilizada como por exemplo: o número de alunos selecionados foi o suficiente para a divisão de tarefas e a utilização de métodos de gerência de projeto como o Canvas que serviu como base para acompanhar e atingir os objetivos. De maneira geral, o resultado obtido dos protótipos desenvolvidos pelos alunos ocasionou o aumento da produtividade e motivação adquirida durante as atividades e melhorou no entendimento de conceitos teóricos da disciplina de ICC. Porém, alguns pontos podem ser reformulados para os próximos alunos ingressantes em projetos como esse.

\section{Conclusões}

Por meio da extensão, a universidade tem o ensejo de transmitir o conhecimento para a comunidade em geral, conhecimento este que é produzido com pesquisa e projetos educacionais. Estes projetos concretizam a interação entre instituição e sociedade com a troca de experiências e a promoção do desenvolvimento de novos processos de ensinoaprendizagem praticados no dia-a-dia dos envolvidos.

Sobre a pesquisa apresentada neste artigo houve certa dificuldade em encontrar relatos na literatura relacionados à atividades extensionistas em que a comunidade trabalhada em questão é a própria comunidade acadêmica. Com isso, a experiência relatada nesta pesquisa espera ser mais uma fonte de informações para outros pesquisadores da área e, além disso, ser um incentivo para que novos trabalhos possam ser desenvolvidos com alunos recém-ingressantes na universidade. Através das atividades de extensão, como as descritas neste trabalho, as pesquisas tornam-se concretas, vivenciadas e experimentadas.

\section{Referências}

BORGES, Jussara Maria (2013). A Gestão Universitária de Projetos de Extensão na Perspectiva da Gestão Social: Um estudo de caso do centro sócio-econômico CSE/UFSC no período de 2009 a 2012. Florianópolis, SC.

BRASIL. Constituição (1988). Constituição da República Federativa do Brasil. Belém: Basa, 1988.

CRUZ, Fábio. Scrum e PMBOK Unidos no Gerenciamento de Projetos. ISBN 978-857452-608-8 Brasport Livros e Multimídia Ltda, Rio de Janeiro, 2013.

GARCIA, R. E.; CORREIA, R. C. M.; SHIMABUKURO, M. H. (2008) "Ensino de Lógica de Programação e Estruturas de Dados para Alunos do Ensino Médio", In: Anais do XXVIIIWEI, CSBC'2008, Belém/PA.

MACEDO, R. S.; PRIETCH, S. S. "Proposta Interdisciplinar de Ensino de Disciplinas da Computação Utilizando Micro-Controlador Arduino". IIENINED - Encontro Nacional de Informática e Educação, 2011, Cascavel/PR.

PMI. Um Guia do Conhecimento em Gerenciamento de Projetos (Guia PMBOK). 5 ed. ISBN - 978-1-62825-007-7 EUA: PMI Global Standart, 2013. 